\title{
БИОБЕЗОПАСНЫЕ НАНОСТРУКТУРИРОВАННЫЕ СТРОИТЕЛЬНЫЕ МАТЕРИАЛЫ С ЗАДАННЫМИ СВОЙСТВАМИ
}

\section{BIOSAFE NANOSTRUCTURED BUILDING MATERIALS WITH DESIRED PROPERTIES}

\author{
М.Б.Тарасов", Изобретатель СССР, (ORCID: 0000-0003-0980-5908), И.П.Погорельский, д.мед.н., проф., \\ (ORCID: 0000 -0001-6293-7366), Р.Ф.Капустин*, д.б.н., проф., (ORCID: 0000-0002-4953-7808), В.И.Хачко*, \\ консультант, (ORCID: 0000-0002-0674-8971), С.И.Цыбульников* , председатель совета, (ORCID: 0000-0002-7727- \\ 0645) / m-tarasov@list.ru \\ M.B.Tarasov*, "Inventor of the USSR", (ORCID: 0000-0003-0980-5908), I.P.Pogorelsky*, Doct. of Sc. (Medical), \\ Prof., (ORCID 0000-0001-6293-7366), R.F.Kapustin*, Doct. of Sc. (Biological), Prof., (ORCID: 0000-0002-4953- \\ 7808), V.I.Khachko*, Consultant, (ORCID: 0000-0002-0674-8971), S.I.Tsybulnikov*, Council Chair (ORCID: \\ 0000-0002-7727-0645)
}

DOI: $10.22184 / 1993-8578.2020 .13 .2 .136 .139$

Получено: 07.02.2020 г.

\begin{abstract}
Нанотехнологии позволяют изготавливать наноматериалы с уникальными физикохимическими характеристиками и потребительскими качествами. Строительные материалы (строительные и кладочные растворы, штукатурка) с модифицирующими добавками могут быть небезопасны при эксплуатации. С целью исследования гостовских характеристик по авторской технологии были изготовлены экспериментальные образцы наноструктурированного строительного раствора - кладочные растворы с различной концентрацией модифицирующей добавки. Экспериментально доказана возможность создания биобезопасных ресурсосберегающих наноструктурированных строительных материалов с заданными характеристиками.

Nanotechnologies facilitate producing nanomaterials with unique physical and chemical properties and consumer qualities. Construction materials (mortar, mason's mortar, plaster) using modifying additives may be unsafe under operating conditions. In order to study GOST characteristics, experimental samples of nanostructured mortar i. e. mason's mortar with different concentrations of modifying additives were manufactured according to the proprietary technology. The possibility of creating bio-safe resource-saving nanostructured construction materials with tailor-made properties has been experimentally proved. This expands the product range enduing it with new consumer qualities and enhances its competitiveness.
\end{abstract}

\section{ВВЕДЕНИЕ}

Нанотехнологии позволяют изготавливать наноматериалы с уникальными физико-химическими характеристиками и потребительскими качествами. Строительные материалы, в частности строительные растворы, кладочные растворы, штукатурка, с модифицирующими добавками могут быть небезопасны в условиях эксплуатации - возможно появление на их поверхностях колоний бактерий и вирусов, опасных для здоровья человека [1-3]. М.Б.Тарасовым разработана биобезопасная наноструктурная модифицирующая добавка, превращающая строительные материалы в наноструктурированные. Дополнительные

Белгородское региональное отделение общественной организации Всероссийской организации изобретателей и рационализаторов / Риbliс Organization of the All-Russian Society of Inventors and Rationalizers, Belgorod Regional Office. 
риски исключены на этапе разработки наноструктурированных ресурсосберегающих и кладочных растворов с заданными характеристиками. Это стало возможным за счет установления ужесточенных требований по биобезопасности [4-6]. Заданы потребительские параметры: эффективная теплопроводность, бактерицидная и вирулицидная эффективность, исключение распада наноматериалов при длительной эксплуатации от воздействия неблагоприятной окружающей среды. Биобезопасность достигается тем, что наночастицы материалов находятся в связанном состоянии и не могут проникать в организм биообъектов через кожу и респираторную систему.

\section{МЕТОДЫ ИССЛЕДОВАНИЯ}

С целью исследования гостовских характеристик по авторской технологии были изготовлены экспериментальные образцы наноструктурированного строительного раствора - кладочные растворы с различной концентрацией модифицирующей добавки. Использовались добавки весом 1 г на 1 дм ${ }^{3}$ готового наноструктурирован ${ }^{-}$ ного продукта. Изготовлено пять серий образцов размером $100 \times 100 \times 100$ мм. Использовался цемент марки M-400. Опалубка удалялась на 7 сутки. Распиловка образцов проведена алмазной пилой на 21 сутки. Температура образцов поддерживалась на уровне $20^{\circ} \mathrm{C}$. Экспериментальные работы по изготовлению образцов выполнены С.И.Цыбульниковым (ООО "НПФ "НаноТехПром"). Дата доставки образцов 25 марта 2011 года. Испытания образцов выполнены в Испытательном центре ИЦ "БГту - сервис": Аттестат аккредитации № POCC RU.0001.22 СЛ 25, зарегистрирован в Федеральном агентстве по техническому регулированию и метрологии 17 июня 2009 года. Дата испытания образцов: 28-31 марта 2011 года. Нормативные документы, в которых установлены требования к испытываемой продукции: определение фактических значений эффективной теплопроводности при стационарном тепловом режиме и естественной влажности. Методика испытаний: ГОСТ 7076-99.

\section{РЕЗУЛЬТАТЫ ИССЛЕДОВАНИЙ}

По результатам получен протокол испытаний № 27 от 31 февраля 2011 года (см. табл. 1). По методике ГОСТ 7076-99 для определения показателя эффективной теплопроводности при стационарном тепловом режиме и естественной влажности образцов из наноструктурного ресурсосберегающего строительного раствора были изготовлены образцы для исследований. В результате выявлена возможность варьирования теплофизических параметров строительных материалов, улучшающих качество конечной продукции (стройматериалов). Через восемь лет хранения опытных образцов при комнатной температуре при визуальном осмотре признаков деструкции не обнаружено. Что подтверждает методологическую основу представления требований к биобезопасности наноструктурированных строительных материлов в качестве базисной при оценке нанотехнологий.

\section{выводы}

Эффективная теплопроводность при естественной влажности испытанных образцов, изготовленных из наноструктурного ресурсосберегающего строительного раствора составляет для серии $1-1,289 \mathrm{BT} / \mathrm{M} \cdot{ }^{\circ} \mathrm{C}$; для серии $3-1,190 \mathrm{BT} / \mathrm{M} \cdot{ }^{\circ} \mathrm{C}$; для серии $5-1,423 \mathrm{BT} / \mathrm{M} \cdot{ }^{\circ} \mathrm{C}$. Экспериментально доказана возможность создания биобезопасных ресурсосберегающих наноструктурированных строительных материалов с заданными характеристиками, что расширяет ассортимент продукции, придавая ей новые потребительские качества и повышает ее конкурентоспособность.

\section{ЛИТЕPATУPA / REFERENCES}

1. Капустин Р.Ф., Старченко Н.Ю. Биофизика, биохимия и молекулярная биология. - Майский: БГСХА, 2011. 271 с.

2. Капустин Р.Ф., Старченко Н.Ю. Судебная медицина. - Белгород: БГУ, 2015. 220 с.

3. Капустин Р.Ф., Старченко Н.Ю. Экология и физиология человека. - Майский: БГСХА, 2012. 117 с.

4. Радилов А.С., Глушкова А.В., Дулов С.А. Экспериментальная оценка токсичности и опасности наноразмерных материалов // Нанотехнологии. Экология. Производство. 2009. № 1. С. 86-89.

5. Свинаренко А.Г. Единые стандарты и наи лучшие практики регулирования в наноиндустрии: устойчивое развитие инновационных предприятий // Нанотехнологии. Экология. Производство. 2012. № 5. С. 56-61.

6. Тарасов М.Б. Особенности патентования, оценки и коммерциализации объектов интеллектуальной собственности - наноструктурных материалов и нанотехнологий // Актуальные вопросы охраны интеллектуальной собственности в условиях действия части четвертой Гражданского Кодекса Российской Федерации. - М.: ФИПС, 2008. С. 95-98. 
Таблица 1. Результаты испытаний по методике ГОСТ 7076-99 для определения показателя эффективной теплопроводности при стационарном тепловом режиме и естественной влажности образцов из наноструктурного ресурсосберегающего строительного раствораж

Table 7. Test results according to the GOST 7076-99 method to determine the index of effective thermal conductivity under steady temperature condition and natural humidity of the samples made of nanostructured resource-saving mortar"

\begin{tabular}{|c|c|c|c|c|c|c|c|}
\hline \multirow[b]{3}{*}{ 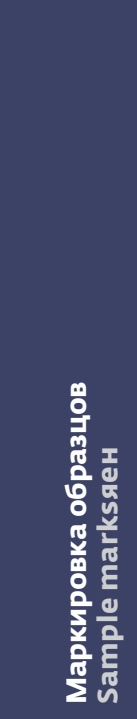 } & \multirow{3}{*}{ 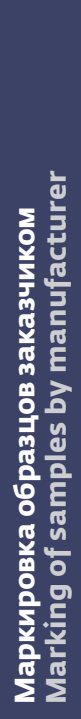 } & \multirow[b]{3}{*}{ 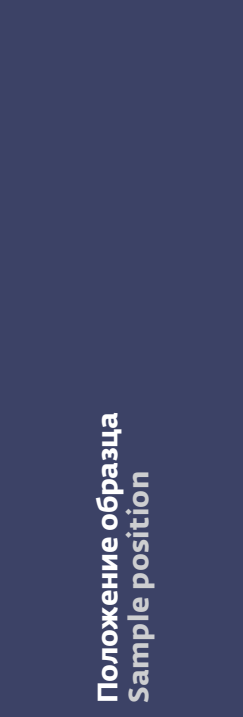 } & \multirow{3}{*}{ 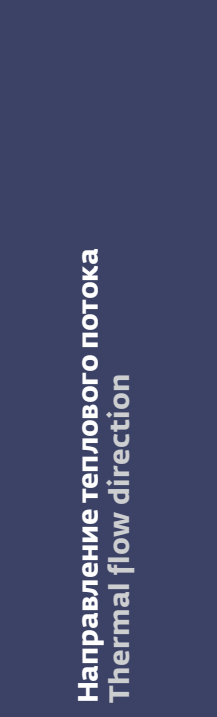 } & \multicolumn{4}{|c|}{$\begin{array}{l}\text { Измеряемые параметры образца } \\
\text { Measured sample parameters }\end{array}$} \\
\hline & & & & \multicolumn{2}{|c|}{ U u } & \multirow{2}{*}{ 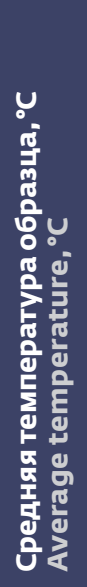 } & \multirow{2}{*}{ 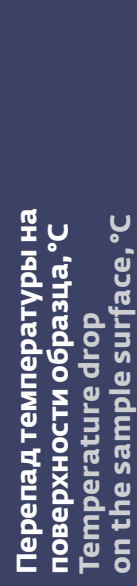 } \\
\hline & & & & 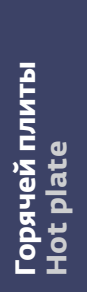 & 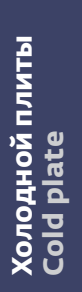 & & \\
\hline 1 & 2 & 3 & 4 & 5 & 6 & 7 & 8 \\
\hline 2-27-1 & 1.1 & $\begin{array}{l}\text { Горизонтальное } \\
\text { Horizontal }\end{array}$ & $\begin{array}{l}\text { Сверху } \rightarrow \text { вниз } \\
\text { Top to bottom }\end{array}$ & 35 & 20 & 27,5 & 15 \\
\hline $2-27-2$ & 1.2 & $\begin{array}{l}\text { Горизонтальное } \\
\text { Horizontal }\end{array}$ & $\begin{array}{l}\text { Сверху } \rightarrow \text { вниз } \\
\text { Top to bottom }\end{array}$ & 35 & 20 & 27,5 & 15 \\
\hline $2-27-3$ & 1.3 & $\begin{array}{l}\text { Горизонтальное } \\
\text { Horizontal }\end{array}$ & $\begin{array}{l}\text { Сверху } \rightarrow \text { вниз } \\
\text { Top to bottom }\end{array}$ & 35 & 20 & 27,5 & 15 \\
\hline \multicolumn{8}{|c|}{$\begin{array}{l}\text { Среднее арифметическое значение по результатам измерений (серия 1) } \\
\text { The arithmetic average of the measurement results (series 1) }\end{array}$} \\
\hline $2-27-4$ & 3.1 & $\begin{array}{l}\text { Горизонтальное } \\
\text { Horizontal }\end{array}$ & $\begin{array}{l}\text { Сверху } \rightarrow \text { вниз } \\
\text { Top to bottom }\end{array}$ & 35 & 20 & 27,5 & 15 \\
\hline $2-27-5$ & 3.2 & $\begin{array}{l}\text { Горизонтальное } \\
\text { Horizontal }\end{array}$ & $\begin{array}{l}\text { Сверху } \rightarrow \text { вниз } \\
\text { Top to bottom }\end{array}$ & 35 & 20 & 27,5 & 15 \\
\hline $2-27-6$ & 3.3 & $\begin{array}{l}\text { Горизонтальное } \\
\text { Horizontal }\end{array}$ & $\begin{array}{l}\text { Сверху } \rightarrow \text { вниз } \\
\text { Top to bottom }\end{array}$ & 35 & 20 & 27,5 & 15 \\
\hline \multicolumn{8}{|c|}{$\begin{array}{l}\text { Среднее арифметическое значение по результатам измерений (серия 3) } \\
\text { The arithmetic mean value according to the measurement results (series 3) }\end{array}$} \\
\hline $2-27-7$ & 5.1 & $\begin{array}{l}\text { Горизонтальное } \\
\text { Horizontal }\end{array}$ & $\begin{array}{l}\text { Сверху } \rightarrow \text { вниз } \\
\text { Top to bottom }\end{array}$ & 35 & 20 & 27,5 & 15 \\
\hline $2-27-8$ & 5.2 & $\begin{array}{l}\text { Горизонтальное } \\
\text { Horizontal }\end{array}$ & $\begin{array}{l}\text { Сверху } \rightarrow \text { вниз } \\
\text { Top to bottom }\end{array}$ & 35 & 20 & 27,5 & 15 \\
\hline $2-27-9$ & 5.3 & $\begin{array}{l}\text { Горизонтальное } \\
\text { Horizontal }\end{array}$ & $\begin{array}{l}\text { Сверху } \rightarrow \text { вниз } \\
\text { Top to bottom }\end{array}$ & 35 & 20 & 27,5 & 15 \\
\hline
\end{tabular}

Отклонения от процедур испытаний отсутствуют, основная относительная погрешность измерения эффективной теплопроводности на установке ИТП-МГ4 (100) не превышает 3\%. / There are no deviations from the test procedures, the main relative error in measuring the effective thermal conductivity at the ITP-MG4 (100) installation does not exceed 3\%. 


\begin{tabular}{|c|c|c|c|c|c|c|}
\hline \multirow[b]{2}{*}{ 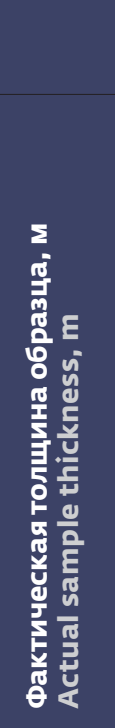 } & \multicolumn{4}{|c|}{$\begin{array}{l}\text { Измеряемые параметры образца } \\
\text { Measured sample parameters }\end{array}$} & \multirow[b]{2}{*}{ 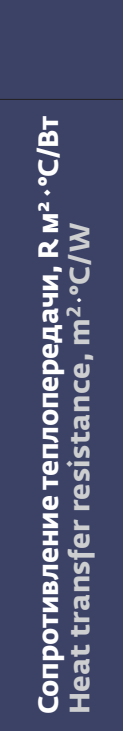 } & \multirow{2}{*}{ 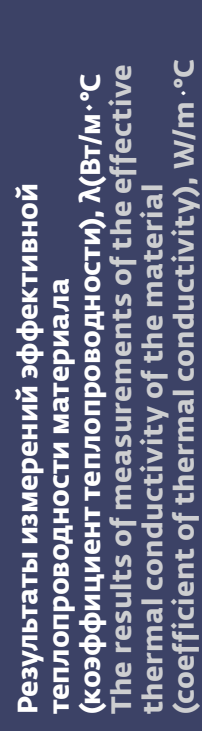 } \\
\hline & 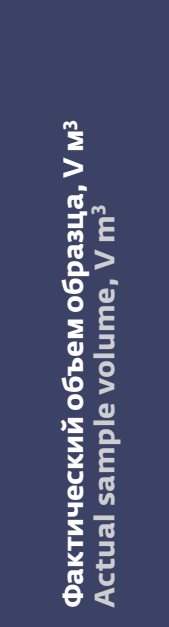 & 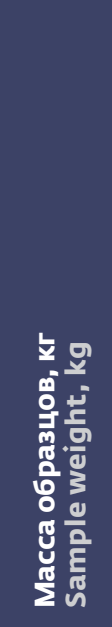 & 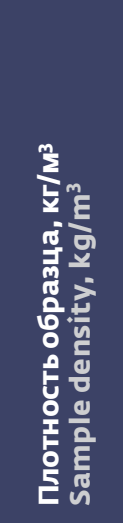 & 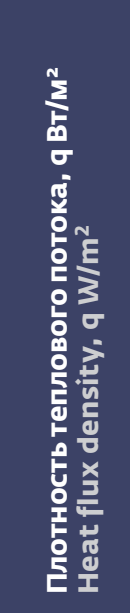 & & \\
\hline 9 & 10 & 11 & 12 & 13 & 14 & 15 \\
\hline 0,02230 & 0,0002254 & 0,4157 & 1844,27 & 1144,40 & 0,01747 & 1,276 \\
\hline 0,02240 & 0,0002270 & 0,4301 & 1894,71 & 1250,89 & 0,01598 & 1,401 \\
\hline 0,02220 & 0,0002262 & 0,4200 & 1856,76 & 1072,97 & 0,01863 & 1,191 \\
\hline & & & & & & 1,289 \\
\hline 0,02220 & 0,0002190 & 0,3815 & 1742,00 & 978,38 & 0,02044 & 1,086 \\
\hline 0,02240 & 0,0002234 & 0,3882 & 1737,69 & 1107,14 & 0,01806 & 1,240 \\
\hline 0,02260 & 0,0002266 & 0,4002 & 1766,10 & 1100,88 & 0,01816 & 1,244 \\
\hline & & & & & & 1,190 \\
\hline 0,02230 & 0,0002236 & 0,4441 & 1986,13 & 1169,50 & 0,01710 & 1,304 \\
\hline 0,02127 & 0,0002116 & 0,4156 & 1964,08 & 1200,00 & 0,01666 & 1,278 \\
\hline 0,02270 & 0,0002290 & 0,4507 & 1968,12 & 1488,10 & 0,01343 & 1,689 \\
\hline & & & & & & 1,423 \\
\hline
\end{tabular}

